\title{
The Estimation of Soil Organic Matter Variation in Arid and Semi-Arid Lands Using Remote Sensing Data
}

\author{
Majed Ibrahim ${ }^{1 *}$, Fatima Ghanem¹, Afnan Al-Salameen ${ }^{1}$, Abdallah Al-Fawwaz ${ }^{2}$ \\ ${ }^{1}$ Geographic Information System and Remote Sensing Department, Erath and Environmental Science Institute, Al Al-Bayt \\ Univesity, Mafraq, Jordan \\ ${ }^{2}$ Biology Department, Science Faculty, Al Al-Bayt University, Mafraq, Jordan \\ Email: *majed.ibrahim@aabu.edu.jo
}

How to cite this paper: Ibrahim, M., Ghanem, F., Al-Salameen, A. and Al-Fawwaz, A. (2019) The Estimation of Soil Organic Matter Variation in Arid and Semi-Arid Lands Using Remote Sensing Data. International Journal of Geosciences, 10, 576-588.

https://doi.org/10.4236/ijg.2019.105033

Received: March 24, 2019

Accepted: May 19, 2019

Published: May 22, 2019

Copyright $\odot 2019$ by author(s) and Scientific Research Publishing Inc. This work is licensed under the Creative Commons Attribution International License (CC BY 4.0).

http://creativecommons.org/licenses/by/4.0/

\section{(c) (i) Open Access}

\begin{abstract}
Soil organic matter (SOM) is an important term to realize soil productivity and quality that is extremely influential on soil physical, chemical and biological processes; SOM is one of the key soil properties controlling nutrient budgets in agricultural production systems and is an important index of soil productivity. Remote sensing (RS) and Geographic Information System (GIS) techniques were used to assess organic matter in soil and determine the relationship between measures SOM in field and digital data to calculate or obtain the correlation coefficients applied to evaluate the strength and direction of the linear relationships. In this study Normalized Difference Vegetation Index (NDVI), Soil Adjusted Vegetation Index (SAVI) and Bare Soil Index (BSI) were used. The results show that the relationship between vegetation indices (NDVI, SAVI) and SOM in whole study area was $\left(\mathrm{R}^{2}=0.19, \mathrm{p}<0.05\right)$, while the relationship in arid areas was $\left(R^{2}=0.01, p<0.05\right)$, and the relationship in semi-arid areas was $\left(\mathrm{R}^{2}=0.13, \mathrm{p}<0.05\right)$. It can be concluded that the diversity in vegetation cover and humidity effects to the relationship between vegetation indices (NDVI, SAVI) and SOM, where these relationships increase rapidly in semi-arid areas more than arid areas. In the other hand about the relationship between SOM and BSI $\left(\mathrm{R}^{2}=0.11, \mathrm{p}<0.05\right)$, soil organic carbon increases with increasing NDVI and decreasing BSI. NDVI, SAVI and BSI were considered a useful index to detect the spatial distribution of SOM concentrations and mapping using remote sensing data.
\end{abstract}

\section{Keywords}

Soil Organic Matter, Remote Sensing, NDVI, SAVI, BSI, Arid and Semi-Arid 


\section{Introduction}

Soil organic matter (SOM) has a significant effect on the soil processes which in turn affects the ability and productivity of the soil. Moreover, it has an impact on water capacity of soil, soil structure and nutrients which increases soil quality [1].

Soil organic matter is a mix component which leads to change soil characteristics and affected by land use, climate, vegetation and soil type. That means the productive ability of agriculture will be compromised by deterioration in soil physical properties if SOM concentration decreased in soil [2]. SOM is carbon-rich material that includes plant, animal and microbial residue in various decomposition stages [3]. SOM is the most important indicator of soil quality and productivity. It also consists of a complex and varied mixture of organic substances [4]. SOM enhances soil function and environmental quality because it binds soil particles together into stable aggregates, thus 1) improving porosity, infiltration and root penetration; 2) reducing runoff and erosion so that the soil in arid, semi-arid, and hot humid regions commonly contains less organic matter than the one in other environments [3]. Therefore, SOM contents affect the soil color where, the dark-colored soil has a higher content of organic matter $(\mathrm{OM})$, and vice versa is true [5].

The quantity of soil organic matter determines the input of organic matter and its rate of oxidation, soil texture, climate, mineralization rate and organic matter decomposition. The clay helps to settle down and limit SOM decomposition. Therefore, soil texture is considered an important factor to agricultural crops as well as rainfall and temperature is a significant factor to the agricultural crops because of its high impact on the OM decomposition rate [6].

SOM includes all OM in the soil except in decayed material. Thus, SOM supports plant because OM acts as an important source of soil nutrients to plants. The OM is reduced by agricultural and economic development [7]. SOM has a key function in exploring the soil and ecological quality [8].

The prime interest for soil experts and environmental directors is studying soil characteristics effectively and opportunely. With the growing request of locative and temporal decision in soil characteristics in different agriculture sectors, traditional laboratory techniques were proved to be unsuitable [5] [9]. Furthermore, the costs of soil test with agriculture systems are costly compared to traditional techniques [5] [10]. In this regard, the range of remote sensing can be explored as substitutional technique for studying soil characteristic [5] [11]. Remote sensing (RS) carries the possibility for identifying soil attributes onto field [5] [12]. This technology assisted to soil exploration and decreased the fieldworks of soil to a large level [5].

Moreover, traditional methods are not always available because of lacking both time and cost connected with sample aggregation. So, it was focused on the employ of remotely sensed data to quantify variation in soil physical characteristic [13]. Soil characteristics description is one of the oldest usage of remotely 
sensed data [13].

Soil scientists are interested in using remote sensing and its applications in soil surveys and soil mapping especially after the evolution of optical sensor in conjunction with field measurements [14] [15] [16]. Remote sensing and Geographic Information System (GIS) techniques have modern and useful techniques to assess SOM at high scales due to the quantities of data necessary and the big sites coverage. For this purpose, these mechanisms have been openly used, adopted and displayed in SOM applications [17].

This study aims to use simple method of results from satellite data and determine the relationship between measured SOM in field and obtained data using remote sensing techniques, find correlation coefficients which applied to evaluate the strength and direction of the linear relationships between variable couples [18]. This paper is characterized by takes into account the soil degradation parameter, where is this parameter effects to the OM particularly in the arid and semi-arid areas.

\section{Materials and Method}

\subsection{Study Area}

Study area is located northeast and northwest Jordan and distributed in two governorates: Mafraq and Irbid governorates Figure 1. The Mediterranean climate is dominant in the region (arid and semi-arid climate). Winter season can be described as cold with low temperature through the night and warm arid summer. Mean early rainfall $350 \mathrm{~mm}$ [19].

The average monthly overflow volumes are in December, January, February

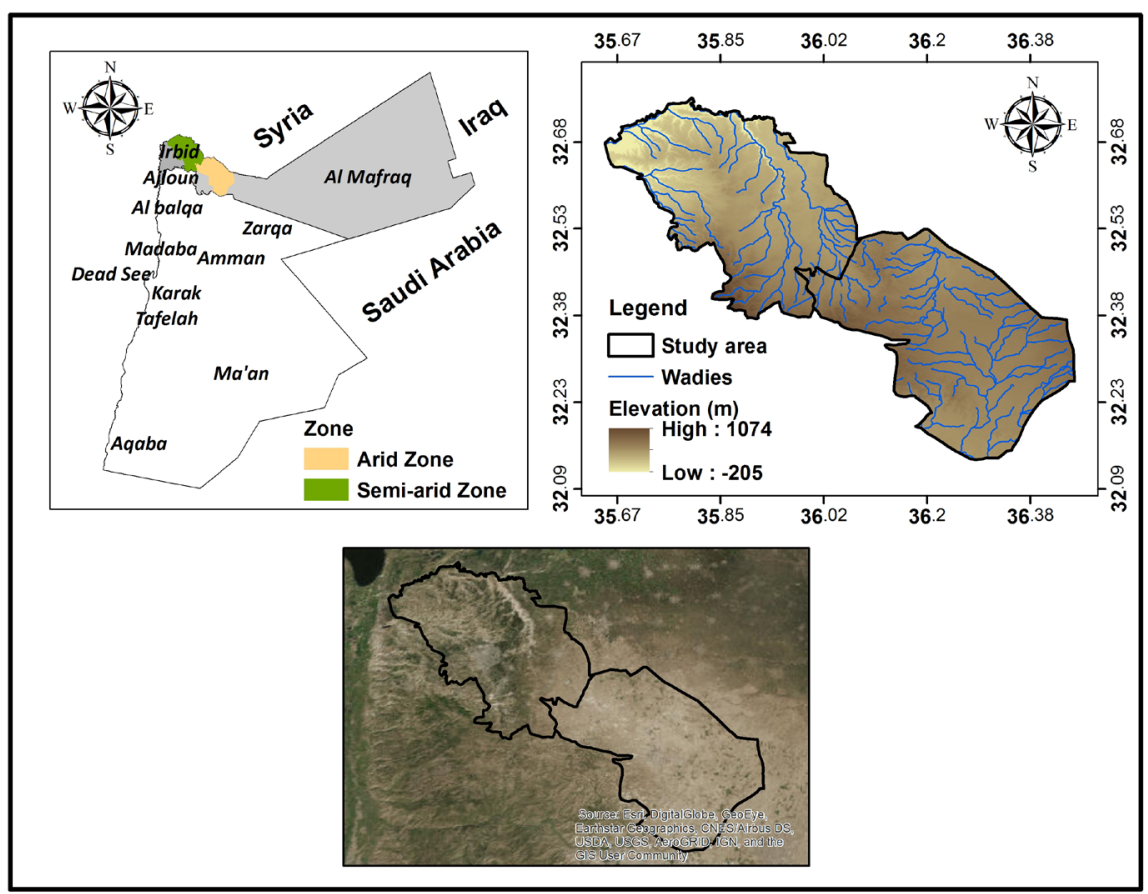

Figure 1. Location of study area. 
and March. Evaporation rate constitutes about $90 \%$ of the aggregate rainfall [20]. Average predestined infiltration rate is about $4 \%-10 \%$ [20] [21]. The climate characteristic of eastern highlands in Jordan is hot in summer and moderate in winters. Low quantities of precipitation happen through comparatively wet months from October to May and they are normally related with the inland steam transport from the Mediterranean Sea. The annual moderate temperature is $17.3^{\circ} \mathrm{C}$. The daily moderate temperature amplitude is from about $8^{\circ} \mathrm{C}$ in the winter to $25^{\circ} \mathrm{C}$ in the summer. Monthly evaporation average varies from about 85 up to 90 millimeters in December and January to 210 millimeters in April, and up to 300 millimeters in May [22], and the evaporation extent 567 millimeters in August [23]. The atmospheric dust, arid climate and low precipitation impact the precipitation water quality thus growing salt content [24] [25].

\subsection{Geological Setting}

The study area consists fundamentally of Paleogene to quaternary continental tuffs and basalts, outcrops back to the Azraq Formation, existing within a rift zone, limited by the NW-SE trending Fuluq and Sirhan faults [26]. Azraq formation base is unconformable on below (older strata) and the top (younger strata) is known by the present-day depositional and erosional surface [27]. Study area contains two groundwater basins Amman-Zerqa basin in Mafraq area and Yarmouk basin in Irbid area [20]. Most of the geologic formations consist of marly layers [24] [25].

\subsection{Methodology}

The methods implemented in this study can be broadly divided into three subsections; fieldwork, image processing and statistics analysis.

\subsubsection{Fieldwork and Lab Work}

Soil Samples from 22 sites located in two zones (semi-arid and arid zones) were carefully collected in plastic bags and appropriately labeled. The soil samples were collected from depth $30 \mathrm{~cm}$. The fieldwork visit includes three types of lands; available agricultural in the study period, abandoned land, and protected land. The purpose of this fieldwork was to collect soil samples from these locations in validation of the land degradation index by assessing soil quality and structure in addition to chemical analyses of these samples. Samples were then classified to different soil texture type by sieve analysis method [28]. In a similar way, the SOM content was measured using the TPDM (Titration of Potassium Dichromate Method) [5] [29]. TPDM actually was used to estimate carbon percentage, Organic Carbon (OC) and Organic Matter (OM) percentages which were calculated based on the following Equation (1):

$$
C \%=\frac{\left[(B-S) \times M \text { of } \mathrm{Fe}^{2+} \times 12 \times 100\right]}{\text { weight of soil }(\mathrm{g}) \times 4}
$$

$B$ is the volume of $\mathrm{Fe}^{2+}$ solution used to titrate blank (mL). $S$ is the volume of 
$\mathrm{Fe}^{2+}$ solution used to titrate sample $(\mathrm{mL})$, and $12 / 4000$ is milliequivalent weight of $C$ in grams to convert easily oxidizable organic $C$ to total $C$, divided by 0.77 (or multiply by 1.30 ) or other experimentally determined correction factor. Therefore, the percentage of organic matter can be estimated by the following Equation (2):

$$
\mathrm{OM} \%=\frac{C \%}{0.58}=C \% \times 1.72
$$

SOM was classified for five classes and used to implement this study after a modified soil-organic-matter test [30] [31] that shown in Table 1.

\subsubsection{Data Acquisition}

The satellite used Landsat 8 OLI (Operational Land Imager) and TIRS (Thermal Infrared Sensor) used in this study in May 2017 path 169 and row 45. The image was obtained from the United States Geological Survey (USGS) Global Visualization (GloVis) site and geometrically corrected and rectified to UTM zone 36. In order to prepare data, managing and analyzing software were conducted as follows: ERDAS IMAGINE 2014 in this study ERDAS was applied in importing and enhancement, as well as ArcGIS 10.5 used to digitizing, indexing and image analysis, geo-referencing, creation of database. Arc map was used for the composition and generation of maps.

\subsubsection{Image Analysis}

Three indices were applied in this research to achieve the aims, where these indices are widely used and these were selected to suit the acquisition data that used in this paper. The Normalized Difference Vegetation Index (NDVI) - which is a normalized ratio of red and near-infrared reflectance. Rouse et al., 1973 have been used in many phonological studies. NDVI is calculated as Equation (3) [32]:

$$
\mathrm{NDVI}=\frac{\lambda \mathrm{NIR}-\lambda \mathrm{R}}{\lambda \mathrm{NIR}+\lambda \mathrm{R}}
$$

where the $(\lambda \mathrm{NIR})$ represent reflection in near infrared, IR $(\lambda \approx 0.8 \mu \mathrm{m})$ regions of the spectrum. $(\lambda \mathrm{R})$ represent surface reflectance in the visible light, $\mathrm{R}(\lambda \approx 0.6$ $\mu \mathrm{m}$, "red"). The large variations in NDVI can be due to variations in soil brightness [33]. The wide regions of bare soil in arid and semi-arid regions may be the

Table 1. Percentages of organic matter in the soil.

\begin{tabular}{cccc}
\hline & Class & Description & Ranking \\
\hline & a & $<1$ (mineral soil, very low organic-matter content) & Very low \\
& b & $1-3$ (mineral soil, moderate organic-matter content) & Low \\
$\begin{array}{c}\text { Organic matter } \\
(\%)\end{array}$ & c & $3.1-15$ (mineral soil, high organic-matter content) & Moderate \\
& d & $15-30$ (organic soil) & High \\
& e & $>30$ (organic carbon soil) & Very high \\
\hline
\end{tabular}


reason of considerable differences in NDVI values and that it's not represent of the actual vegetation cover [34] [35] [36].

The NDVI is measured by satellite sensors. Rouse et al. (1973) [32] were the first to write a report of NDVI [37]. Many factors affect NDVI values other than the vegetation itself such as total plant cover, plant photosynthetic activity, biomass, and plant stress. Soil and atmosphere have been shown to have a great effect on the NDVI [38] [39] [40].

The Soil Adjusted Vegetation Index (SAVI) (Huete, 1988) [41] was also used in this study. SAVI is an adjustment on the (NDVI) that decreases soil effect, it was developed by (Huete 1988; Huete et al., 1987; Kaufman et al., 1902; Epiphanio et al., 1995) [38] [39] [40] [41], and is expressed by the following Equation (4):

$$
\mathrm{SAVI}=\frac{\lambda \mathrm{NIR}-\lambda \mathrm{R}}{\lambda \mathrm{NIR}+\lambda \mathrm{R}} \times(1+L)
$$

where the NIR represents reflection in near infrared (730 - $1000 \mathrm{~nm})$, RED represents surface reflectance in the visible light $(550-700 \mathrm{~nm})$ and $L$ is soil adjustment factor (Ray et al., 2001). The value of $L$ varies by the amount or cover of green vegetation and varying from 0 (close canopy cover) to 1 (open canopy cover): in very high vegetation regions $L=0$; and in areas with no green vegetation, $L=1$. Generally, an $L=0.5$ works well in most situations and is the default value used.

However, removal of plant covers jeopardizes the carbon cycle and decreases the percentage of organic matter in the soil, as well as resulting in a degradation of physical soil properties and structure [42]. The removal of vegetation processes increases erosion and land degradation, particularly in the semi-arid and dry sub-humid areas that have a high sensitivity to desertification and degradation. Table 2 shows three classes of vegetation cover that were used in this study [42] [43] [44].

Bare Soil Index (BSI) value was estimated using combines blue, red, green and near-infrared bands to detect the soil changes of the Landsat 8 OLI and TM data to determine the condition of the uncovered soil by vegetation which is helpful to determine the state of the soil organic matter on the region. BSI is described by the following Equation (5) according to Jamalabad \& Abkar (2004) [45]:

$$
\mathrm{BSI}=\left[\frac{(\lambda \mathrm{R}+\lambda \mathrm{G})-(\lambda \mathrm{R}+\lambda \mathrm{B})}{(\lambda \mathrm{NIR}+\lambda \mathrm{G})+(\lambda \mathrm{R}+\lambda \mathrm{B})} \times 100\right]+100
$$

Table 2. vegetation removal percentages.

\begin{tabular}{ccc}
\hline Parameter & Class & Description \\
\hline Vegetation Removal (\%) & 1 & Low, $<1.5$ \\
& 2 & Moderate, $1.5-2.5$ \\
& 3 & High, $>2.5$ \\
\hline
\end{tabular}




\section{Results and Discussions}

Results of laboratory measurements of soil indicate that organic matter percentage in the soil (Organic Carbon) in study area varies from low to very low based on Table 1 . SOM was ranging between $(0.38 \%$ to $0.9 \%)$ in the areas with relatively arid climate condition with mean value of $0.68 \pm 0.156$, while in areas with relatively semi-arid (humid) climate condition SOM ranged from $(0.59 \%$ to $1.68 \%$ ) with mean value of $0.89 \pm 0.32$. Statistical analysis of this study relies on the five variables which were used; SOM, water content, NDVI, SAVI and BSI in the study area shown in Table 3.

\subsection{Relation between Vegetation Index and SOM}

It was found that the relationship between Vegetation Index (NDVI, SAVI) and SOM was statistically significant and the $\left(\mathrm{R}^{2}=0.19, \mathrm{p}<0.05\right)$, as shown in Table 4 and Figure 2, the form of the model that appears this relationship is as following Equation (6):

$$
\mathrm{SOM}=2.96 \times \mathrm{NDVI}+0.36
$$

This model describes the relation between (NDVI, SAVI) and SOM in both arid and semi-arid regions. However, the relationship is relatively different in arid areas from that in semi-arid areas $\left(\mathrm{R}^{2}=0.01, \mathrm{p}<0.05\right),\left(\mathrm{R}^{2}=0.13, \mathrm{p}<0.05\right)$, respectively. It was also found that the relationship between (NDVI, SAVI) and SOM increases in semi-arid areas that have diversity in vegetation cover and humidity more than arid areas that have dry climate change but do not have variety in vegetation cover. The means of laboratory measurement of soil in both arid and semi-arid or humidity regions were $(0.68,0.89)$, respectively.

\subsection{Relation between Vegetation Index and BSI}

The relationship between vegetation index such as NDV and BSI is represented

Table 3. The statistical analysis for four variables used; SOM, NDVI, SAVI and BSI in the study area.

\begin{tabular}{ccccc}
\hline Parameter & SOM & NDVI & SAVI & BSI \\
\hline MIN & 0.38 & 0.08 & 0.12 & 100.11 \\
MAX & 1.68 & 0.19 & 0.28 & 102.96 \\
MEAN & 0.78 & 0.14 & 0.21 & 101.32 \\
SD & 0.27 & 0.04 & 0.06 & 1.01 \\
S.DE & 0.06 & 0.01 & 0.01 & 0.24 \\
\hline
\end{tabular}

Table 4. The statistically significant relationship for four variables used.

\begin{tabular}{ccccc}
\hline & SOM & NDVI & SAVI & BSI \\
\hline SOM & 1 & & & \\
NDVI & 0.1874 & 1 & & \\
SAVI & 0.1874 & 1 & 1 & \\
BSI & 0.1136 & 0.8114 & 0.8114 & 1 \\
\hline
\end{tabular}




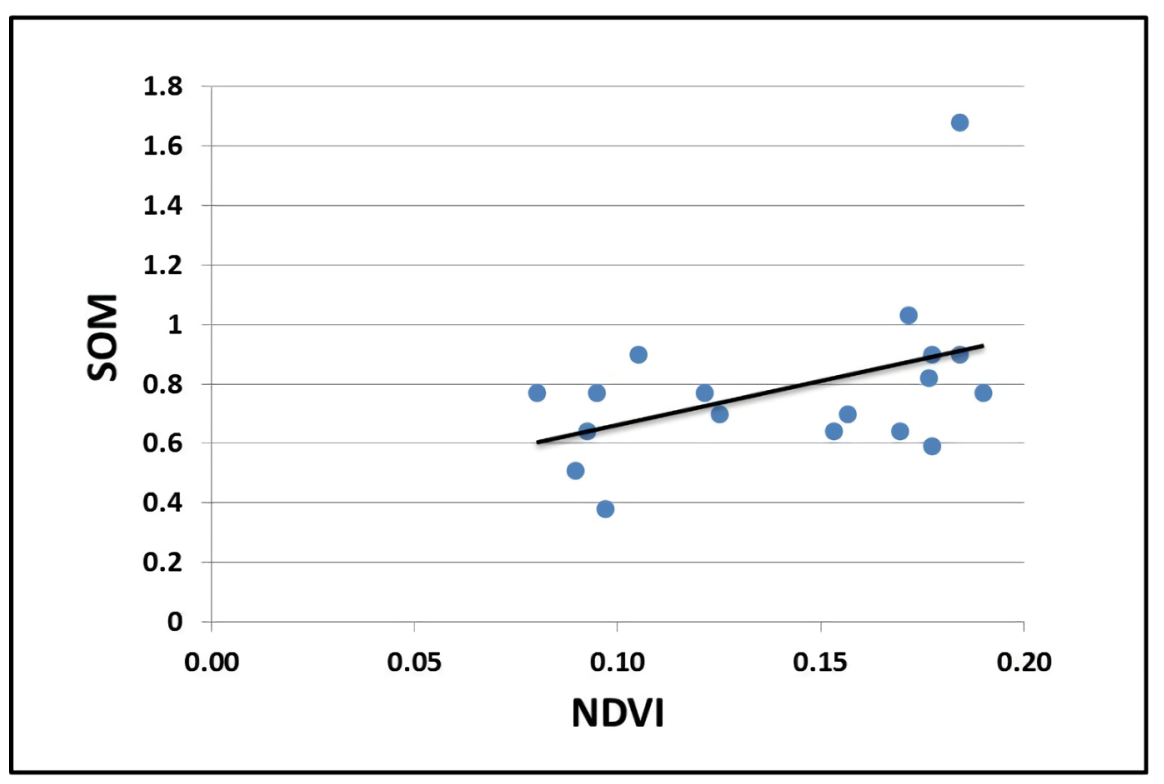

Figure 2. Relation between vegetation index and SOM.

in Figure 3. The results shown a statistically significant relation between NDVI and BSI $\left(\mathrm{R}^{2}=0.81, \mathrm{p}<0.05\right)$. That increasing degradation conditions mean decrease in rainfall and increase in dry climate that lead to decrease in NDVI.

\subsection{Relation between BSI and SOM}

It was found that there are differences in the relationship between measured SOM and Bare soil Index (BSI). This relation is shown in Figure 4. The results showed a statistically significant relation between measured SOM and BSI $\left(\mathrm{R}^{2}=\right.$ $0.114, \mathrm{p}<0.05)$. The form of the model that appears this relationship is as following Equation (7):

$$
\mathrm{SOM}=0.09 \times \mathrm{BSI}-9.99
$$

The outcomes also indicated that SOC increases with increasing NDVI and decreasing BSI. Finally, the multiple regression models were fitted into ArcGIS to generate the digital SOC map using raster calculator Figure 5. The statistical correlation of the relationship between the estimated SOM and measured SOM was calculated $\left(R^{2}=0.23\right)$ as shown in Figure 6 .

It was also found that the regions, that have both a high rainfall (250 - 400 $\mathrm{mm}$ annually) and a good vegetation percentage, have the high concentrations relatively of SOM. These regions were distributed in eastern part boarders and some regions in the central part of study area which is semi-arid. The region covered by urban, rock and sand has extremely low SOC values about zero, while the central part and southern-east boarders have low of SOC values and have a low rainfall relatively (less than $200 \mathrm{~mm}$ annually) and a high temperature.

\section{Conclusion}

The SOM measured values showed a good correlation with used indices, where 




Figure 3. Relation between vegetation index and BSI.

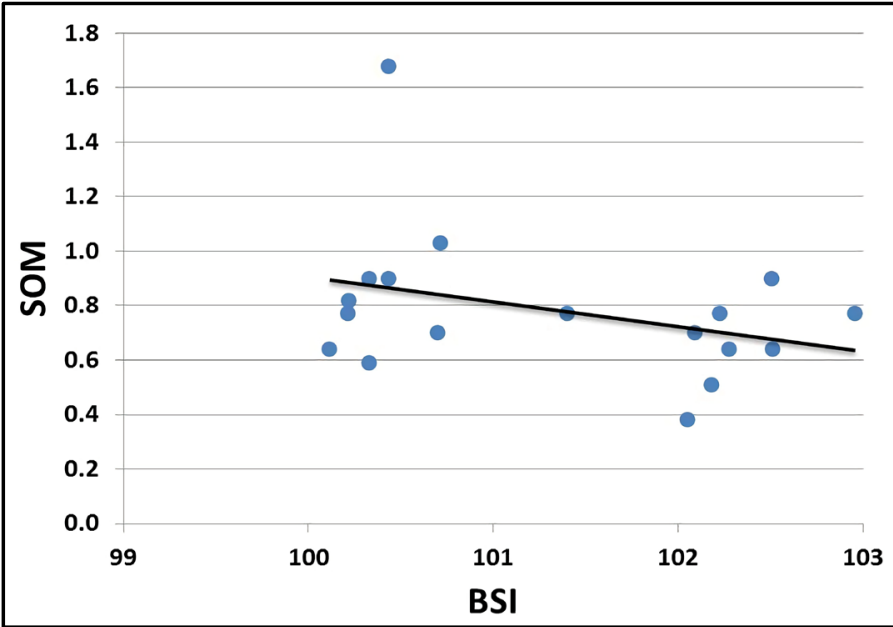

Figure 4. Relation between BSI and SOM.



Figure 5. Digital SOM Map by model. 


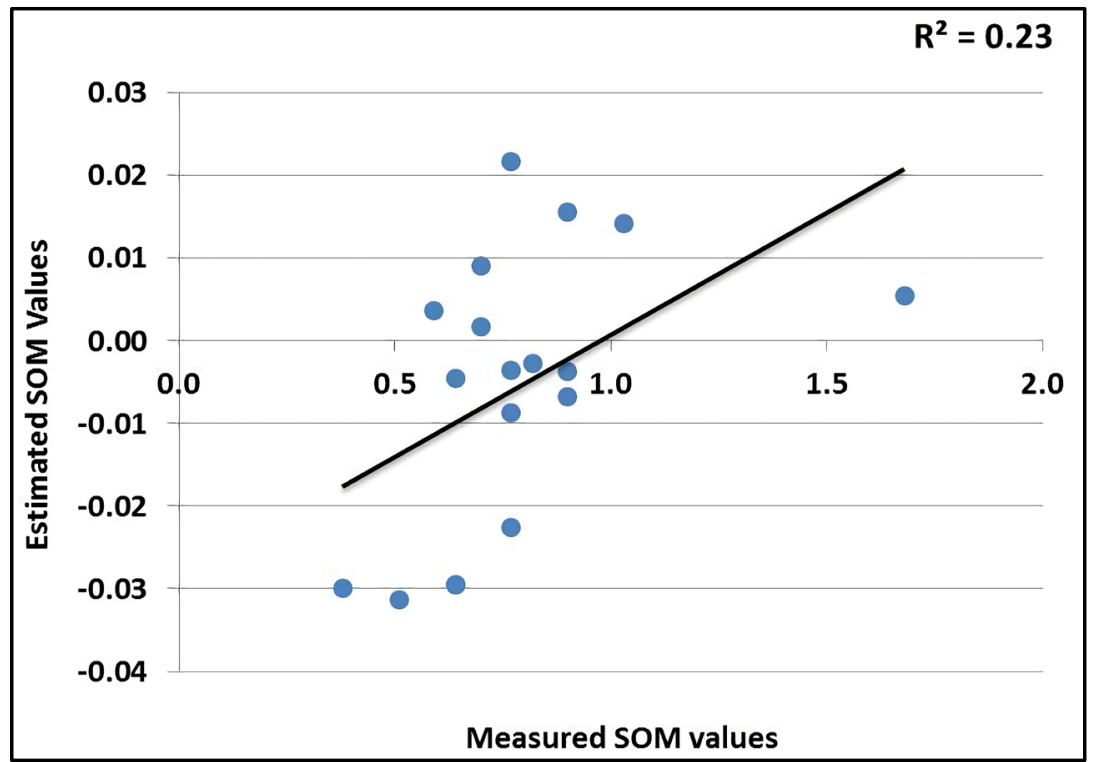

Figure 6. The relationship between the estimated SOM and measured SOM.

this study suggested that these vegetation indices (NDVI and SAVI) and bare soil index (BSI) are helpful to detect the spatial distribution of SOM concentrations. In addition the statistical analysis results were useful to analyse measured values in the field and to understand the relationships that helped to estimated SOM concentrations by remote sensing data, although the pixel size $(30 \mathrm{~m} \times 30$ $\mathrm{m}$ ) used in the study area was relatively large with this area, which reflected the variation in SOM concentrations. The results of this study support the approach that the remote sensing data are useful to detect and investigate the environmental changes. This approach was used through mapping and determines the spatial distribution of SOM concentrations using spectral indices processed remote sensing data; techniques could be effective to monitor and manage soil.

\section{Acknowledgements}

Authors are thankful to anonymous reviewers for their constructive comments and suggestions to improve the manuscript. Authors also are thankful to Department of Earth and Environmental Sciences members in Al Al-Bayt University for providing all necessary support.

\section{Conflicts of Interest}

The authors declare no conflicts of interest regarding the publication of this paper.

\section{References}

[1] Wu, C., Wu, J., Luo, Y., Zhang, L. and De Gloria, S.D. (2009) Spatial Prediction of Soil Organic Matter Content Using Cokriging with Remotely Sensed Data. Soil Science Society of America Journal, 73, 1202-1208.

https://doi.org/10.2136/sssaj2008.0045 
[2] Loveland, P. and Webb, J. (2003) Is There a Critical Level of Organic Matter in the Agricultural Soils of Temperate Regions: A Review. Soil and Tillage Research, 70, 1-18. https://doi.org/10.1016/S0167-1987(02)00139-3

[3] USDA (United State Department of Agriculture) (2001) USDA, Natural Resources Conservation Service. Rangeland Soil Quality_Organic Matter. Soil Quality Information Sheet. Rangeland Sheet 6.

[4] Jankauskas, B., Jankauskienè, G. and Fullen, M.A. (2007) Relationships between Soil Organic Matter Content and Soil Erosion Severity in Albeluvisols of the Žemaičiai Uplands. Ekologija, 53, 21-28.

[5] Ahmed, Z. and Iqbal, J. (2014) Evaluation of Landsat TM5 Multispectral Data for Automated Mapping of Surface Soil Texture and Organic Matter in GIS. European Journal of Remote Sensing, 47, 557-573. https://doi.org/10.5721/EuJRS20144731

[6] Johnston, A.E., Poulton, P.R. and Coleman, K. (2009) Soil Organic Matter: Its Importance in Sustainable Agriculture and Carbon Dioxide Fluxes. Advances in Agronomy, 101, 1-57. https://doi.org/10.1016/S0065-2113(08)00801-8

[7] Kerdsueb, P. and Teartisup, P. (2014) The Use of Geoinformatics for Estimating Soil Organic Matter in Central Plain of Thailand. International Journal of Environmental Science and Development, 5, 282.

https://doi.org/10.7763/IJESD.2014.V5.492

[8] Mirzaee, S., Ghorbani-Dashtaki, S., Mohammadi, J., Asadi, H. and Asadzadeh, F. (2016) Spatial Variability of Soil Organic Matter Using Remote Sensing Data. Catena, 145, 118-127. https://doi.org/10.1016/j.catena.2016.05.023

[9] Ehsani, M.R., Upadhyaya, S.K., Slaughter, D., Shafii, S. and Pelletier, M. (1999) A NIR Technique for Rapid Determination of Soil Mineral Nitrogen. Precision Agriculture, 1, 217-234. https://doi.org/10.1023/A:1009916108990

[10] Ge, Y., Thomasson, J.A., Morgan, C.L. and Searcy, S.W. (2007) VNIR Diffuse Reflectance Spectroscopy for Agricultural Soil Property Determination Based on Regression-Kriging. Transactions of the American Society of Agricultural and Biological Engineers, 50, 1081-1092. https://doi.org/10.13031/2013.23122

[11] Galvao, L.S., Vitorello, Í. and Roberto, A. (1997) Relationships of Spectral Reflectance and Color among Surface and Subsurface Horizons of Tropical Soil Profiles. Remote Sensing of Environment, 61, 24-33. https://doi.org/10.1016/S0034-4257(96)00219-2

[12] Mulla, D.J., Sekely, A.C. and Beatty, M. (2000) Evaluation of Remote Sensing and Targeted Soil Sampling for Variable Rate Application of Lime. Proceedings of the 5th International Conference on Precision Agriculture, Bloomington, 16-19 July 2000, 1-14.

[13] Barnes, E.M., Sudduth, K.A., Hummel, J.W., Lesch, S.M., Corwin, D.L., Yang, C. and Bausch, W.C. (2003) Remote- and Ground-Based Sensor Techniques to Map Soil Properties. Photogrammetric Engineering \& Remote Sensing, 69, 619-630. https://doi.org/10.14358/PERS.69.6.619

[14] Ben-Dor, E., Irons, J.R. andEpema, G.F. (1999) Soil Reflectante. In: Rencz, A.N. and Ryerson, R.A., Eds., Manual of Remote Sensing. Remote Sensing for Earth Science, Wiley, Hoboken, 111-187.

[15] Taylor, G.R. and Dehan, R.L. (2000) Mapping Soil Salinity with Hyperspectral Imagery. Proceedings of 14 th International Conference on Applied Geologic Remote Sensing, Las Vegas, 6-8 November 2000, 512-519.

[16] Mandal, U.K. (2016) Spectral Color Indices Based Geospatial Modeling of Soil Or- 
ganic Matter in Chitwan District, Nepal. The International Archives of the Photogrammetry, Remote Sensing and Spatial Information Sciences, Volume XLI-B2, Prague, 12-19 July 2016, 43-48.

https://doi.org/10.5194/isprsarchives-XLI-B2-43-2016

[17] Parveen, R. and Kumar, U. (2012) Integrated Approach of Universal Soil Loss Equation (USLE) and Geographical Information System (GIS) for Soil Loss Risk Assessment in Upper South Koel Basin, Jharkhand. Journal of Geographic Information System, 4, 588. https://doi.org/10.4236/jgis.2012.46061

[18] Mukaka, M. (2012) A Guide to Appropriate Use of Correlation Coefficient in Medical Research. Malawi Medical Journal, 24, 69-71. https://doi.org/10.4236/jwarp.2015.77047

[19] Ibrahim, M. and Koch, B. (2015) Assessment and Mapping of Groundwater Vulnerability Using SAR Concentrations and GIS: A Case Study in Al-Mafraq, Jordan. Journal of Water Resource and Protection, 7, 588.

[20] WAJ (1989) Review of Water Resources Development and Use in Jordan. Ministry of Water and Irrigation of Jordan, Amman.

[21] Al-Mahamid, J.S. (1998) Three Dimensional Numerical Model for Groundwater Flow and Contamination Transport of Dhuleil-Hallaqbat Aquifer System. Jordan University.

[22] Chahata, M., Livnat, A. and Thorpe, R. (1997) Water Quality Improvement and Conservation Project, Feasibility Study of Artificial Recharge in Jordan Case of WadiMadoneh and WadiButum. Amman-Jordan.

[23] Al-Qaisi, B.M. (2010) Climate Change Effects on Water Resources in Amman Zarqa Basin-Jordan. Individual Project Report for Climate Change Mitigation and Adaptation.

[24] Salameh, E. (1996) Water Quality Degradation in Jordan. Friedrich Ebert Stiftung and Royal Society for the Conservation of Nature, Amman, 178.

[25] Eraifej, N. and Abu-Jaber, N. (1999) Geochemistry and Pollution of Shallow Aquifers in the Mafraq Area, North Jordan. Environmental Geology, 37, 162-170. https://doi.org/10.1007/s002540050373

[26] Rabb'a, I.A. (1997) Geological Map of Al VUmari (Abar Al Hazim) Natural Resources Authority, Geology Directorate, Amman.

[27] Turner, B.R. and Makhlouf, I. (2005) Quaternary Sandstones, Northeast Jordan: Age, Depositional Environments and Climatic Implications. Palaeogeography, Palaeoclimatology, Palaeoecology, 229, 230-250.

https://doi.org/10.1016/j.palaeo.2005.06.024

[28] Day, P.R. (1965) Particle Fractionation and Particle Size Analysis. Methods of Soil Analysis. Part 1. Agronomy, 9, 545-566.

[29] Walkley, A. (1947) A Critical Examination of a Rapid Method for Determining Organic Carbon in Soils-Effect of Variations in Digestion Conditions and of Inorganic Soil Constituents. Soil Science, 63, 251-264. https://doi.org/10.1097/00010694-194704000-00001

[30] Boyd, C.E., Wood, C.W. and Thunjai, T. (2002) Pond Soil Characteristics and Dynamics of Soil Organic Matter and Nutrients. In: McElwee, K., Lewis, K., Nidiffer, M. and Buitrago, P., Eds., Nineteenth Annual Technical Report, Pond Dynamics/Aquaculture CRSP, Oregon State University, Corvallis, 1-10.

[31] Ibrahim, M. (2014) The Use of Geoinformatics in Investigating the Impact of Agricultural Activities between 1990 and 2010 on Land Degradation in NE of Jordan. 
Doctoral Dissertation, Freiburg University, Freiburg im Breisgau.

[32] Rouse, J.W., Haas, R.H., Schell, J.A. and Deering, D.W. (1973) Monitoring Vegetation Systems in the Great Plains with ERTS. Third ERTS Symposium, Washington DC, 10-14 December 1973, NASA SP-351 I, 309-317.

[33] Carlson, T.N. and Ripley, D.A. (1997) On the Relation between NDVI, Fractional Vegetation Cover, and Leaf Area Index. Remote Sensing of Environment, 62, 241-252. https://doi.org/10.1016/S0034-4257(97)00104-1

[34] Huete, A.R. (1985) Spectral Response of a Plant Canopy with Different Soil Backgrounds. Remote Sensing of Environment, 17, 37-53. https://doi.org/10.1016/0034-4257(85)90111-7

[35] Huete, A.R. and Tucker, C.J. (1991) Investigation of Soil Influences in AVHRR Red and Near-Infrared Vegetation Index Imagery. International Journal of Remote Sensing, 12, 1223-1242. https://doi.org/10.1080/01431169108929723

[36] Anyamba, A. and Tucker, C.J. (2005) Analysis of Sahelian Vegetation Dynamics Using NOAA-AVHRR NDVI Data from 1981-2003. Journal of Arid Environments, 63, 596-614. https://doi.org/10.1016/j.jaridenv.2005.03.007

[37] Pettorelli, N., Ryan, S., Mueller, T., Bunnefeld, N., Jędrzejewska, B., Lima, M. and Kausrud, K. (2011) The Normalized Difference Vegetation Index (NDVI): Unforeseen Successes in Animal Ecology. Climate Research, 46, 15-27. https://doi.org/10.3354/cr00936

[38] Huete, A.R. and Jackson, R.D. (1987) Suitability of Spectral Indices for Evaluating Vegetation Characteristics on Arid Environments. Remote Sensing of Environment, 23, 213-232. https://doi.org/10.1016/0034-4257(87)90038-1

[39] Kaufman, Y. and Tanr, D. (1992) Atmospherically Resistant Vegetation Index (ARVI) for EOS-MODIS. IEEE Transactions on Geoscience and Remote Sensing, 30, 261-270. https://doi.org/10.1109/36.134076

[40] Epiphanio, J.N. and Huete, A.R. (1995) Dependence of NDVI and SAVI on Sun/Sensor Geometry and Its Effect on fAPAR Relationships in Alfalfa. Remote Sensing of Environment, 51, 351-360. https://doi.org/10.1016/0034-4257(94)00110-9

[41] Huete, A.R. (1988) A Soil-Adjusted Vegetation Index (SAVI). Remote Sensing of Environment, 25, 295-309. https://doi.org/10.1016/0034-4257(88)90106-X

[42] Albaladejo, J., Martinez-Mena, M., Roldan, A. and Castillo, X. (1998) Soil Degradation and Desertification Induced by Vegetation Removal in a Semiarid Environment. Soil Use and Management, 14, 1-5. https://doi.org/10.1111/j.1475-2743.1998.tb00602.x

[43] DESIRE (2007) Disseminating Educational Science Innovation \& Research in Europe.

http://www.desire-his.eu/wimba/WP2.1\%20Indicators\%20in\%20the\%20study\%20si tes\%20(Report\%2066\%20D211\%20Mar10)/index.htm

[44] Ibrahim, M. (2016) Temporal Interpretation for Land Use/Land Cover Changes Using Multispectral Images: Irbid as a Case Study. Journal of Natural Sciences Research, 6, 100-104.

[45] Jamalabad, M. and Abkar, A. (2004) Forest Canopy Density Monitoring, Using Satellite Images. In: 20th ISPRS Congress, International Society for Photogrammetry and Remote Sensing, Istanbul, 12-23. 